\title{
ESCOLA SEM GESTOR: ALGUNS APONTAMENTOS
}

DOI: 10.5902/2318133832384

\author{
Ronaldo Gomes Pinto \\ Ricardo Alexandre Marangoni \\ Faculdade de Conchas, Brasil.
}

\begin{abstract}
Resumo
Relata-se neste texto os resultados de um trabalho que teve como objetivo investigar as representações de professores acerca de uma escola funcionar sem a presença do gestor. A literatura mostra a persistência do modelo hierarquizado de gestão, embora existam estudos que indicam outras possibilidades de gestão escolar (Paro, 2011). Articulou-se dois momentos: o primeiro corresponde ao corpus teórico, cujas abordagens estão relacionadas à legislação educacional e os estudos de Abdian, Oliveira e Jesus (2013), Marangoni (2017), Paro (2011). O segundo abrange a coleta de dados, tendo como questões norteadoras: o que os professores entendem sobre o papel do gestor escolar? O que eles pensam acerca da escola funcionar sem a presença do gestor? Os resultados apontaram que é possível outros modos de gestão escolar. Palavras-chave: gestor escolar; o papel do gestor; modos de gestão escolar.
\end{abstract}

\section{SCHOOL WITHOUT MANAGER: SOME NOTES}

\begin{abstract}
This work had as objective to investigate the representations of teachers about a school to function without the presence of the manager. The literature shows the persistence of the hierarchical management model, although there are studies that indicate other possibilities of school management (Paro, 2011). The first one corresponds to the theoretical corpus, whose approaches are related to the educational legislation and the studies of Abdian, Oliveira and Jesus (2013), Marangoni (2017), Paro (2011). The second one covers data collection, with the guiding questions: what do teachers understand about the role of the school manager? What do they think about school functioning without the presence of the manager? The results pointed out that other modes of school management are possible.
\end{abstract}

Key-words: school manager; the role of the manager; modes of school management. 


\section{Introdução}

ste estudo surgiu a partir do projeto interdisciplinar realizado no $2^{\circ}$ semestre de 2016, no curso de Pedagogia da Faculdade de Conchas. A proposta foi desenvolvida numa escola do campo que não tinha a presença de um gestor para acompanhar as atividades escolares. Aliado a esta experiência inesquecível, vale ressaltar que a disciplina de Gestão Educacional nos ajudou a questionar a estrutura da escola e a persistência do modelo hierarquizado de gestão adotado na maioria das instituições escolares.

A nossa vivência com o projeto interdisciplinar e a disciplina de Gestão Educacional despertou-nos o interesse pela investigação da questão: o que pensam os professores acerca da escola funcionar sem a presença do gestor?

A revisão de literatura indicou que existem diferentes abordagens acerca da temática. Inicialmente nos aproximamos de Abdian; Oliveira; Jesus (2013); Marangoni (2017) e Paro (2011), que apresentam uma discussão sobre o trabalho do gestor e os modos de gestão escolar. $O$ objetivo principal é investigar o que os professores pensam acerca do funcionamento escolar sem a presença do gestor.

\section{O papel do diretor de escola segundo a literatura}

Abordar o papel do diretor não é tarefa simples. Isso ocorre porque a discussão não é recente na área de gestão escolar. Segundo Ribeiro (1968) e Lourenço Filho (2007), citados por Abdian; Oliveira; Jesus (2013, p. 980), a "função do diretor/administrador escolar concentra-se na liderança".

O diretor de escola, designado como gestor, continua exercendo a função de líder. É ele quem conduz todo o funcionamento da escola, tanto na parte pedagógica, quanto na burocrática e financeira da instituição. Dessa forma, observamos dois posicionamentos. Aqueles que defendem que cabe ao gestor liderar e, aqueles que defendem que cabe a ele mediar. Segundo Marangoni (2017),

podemos dizer que gerir uma escola é não dirigir. A expressão dirigir, já como apontado anteriormente nos incomoda, porque pressupõe a ideia de liderança ${ }^{4}$. Para nós, que defendemos a gestão democrática e participativa preferimos adotar o termo articular e, portanto, o gestor seria o articulador da escola. Isso não reflete simplesmente uma mudança de termo, mas uma mudança de concepção e de postura. (p. 60)

Segundo Marangoni (2017) a mudança de líder para articulador expressa uma mudança de concepção e de postura, de relações verticais para relações horizontais. Considerando a estrutura hierárquica da escola, as relações verticais estabelecem-se a partir daqueles que mandam sobre aqueles que não mandam.

Outro aspecto ao qual chamamos a atenção é para a comunicação realizada pelos gestores. A comunicação do gestor é importante para a instituição, pois ora ela resolve ou evita problemas, ora, ela cria problemas. Nossas observações indicam que o modo como estas informações chegam podem não resolver problemas e sim criar conflitos com 
os docentes e discentes. Essa situação parece-nos estar associada a forma como se organiza o sistema e a rede de ensino, aliada a postura do gestor que, comumentemente, assume a posição de líder.

A esse respeito, do sistema de organização e gestão da escola, Libâneo (2015) afirma que

o diretor coordena, organiza e gerencia todas as atividades da escola, auxiliado pelos demais componentes do corpo de especialistas e de técnicos-administrativos, atendendo às leis, regulamentos e determinações dos órgãos superiores do sistema de ensino e às decisões no âmbito da escola assumidas pela equipe escolar e pela comunidade. $O$ assistente de diretor desempenha as mesmas funções na condição de substituto eventual do diretor. ( p. 108)

Nesse caso, o Libâneo (2015) considera o gestor como sendo o coordenador, o organizador e o gerenciador de todas as atividades da escola. Ele, auxiliado por outros técnico-administrativos, é o responsável pela implantação das políticas educacionais elaboradas pelos órgãos superiores.

Paro (2011) apresenta uma proposta de colegiado diretivo. O autor propõe que o colegiado passe de deliberativo para diretivo. O colegiado diretivo é um órgão de direção, responsável pela organização administrativa e pedagógica da escola. É constituído por representantes dos diversos segmentos e

\begin{abstract}
uma das maiores dificuldades encontradas pelos conselhos escolares para promoverem a democratização da escola tem sido precisamente o fato de que, por mais deliberativo que seja, ele nunca é diretivo, cabendo essa incumbência ao diretor escolar que, como responsável último pela instituição, se vê obrigado a atender, em primeiro lugar, os interesses do Estado. Quando as deliberações do conselho de escola conflitam com determinações dos escalões superiores do sistema é a estes que o diretor se vê compelido a atender. A estrutura administrativa da escola está disposta de tal maneira que o diretor é sempre considerado o representante do Estado na unidade. (p. 61)
\end{abstract}

Essa proposta de Paro (2011), parece-nos interessante e acreditamos ser a que mais se aproxima de uma gestão democrática e participativa. Marangoni (2017, p. 62), também, alerta-nos que "os órgãos colegiados por si, não garantem o exercício democrático e participativo, devendo nós, mudarmos de postura para que atinjamos tais condições". Ele aponta que em muitos casos, os órgãos colegiados oferecem aos seus membros uma falsa sensação de participação, ratificando decisões tomadas nos "bastidores". Diríamos que estamos diante de um desafio a ser enfrentado.

\title{
O papel do diretor de escola segundo a legislação municipal
}

Optamos por nos aproximar da lei complementar n. 246, de 27 de abril de 2016, que "dispõe sobre o plano de carreira e remuneração dos profissionais da Educação Básica do município de Conchas e dá outras providências". Ela expõe o que a Secretaria Municipal de Educação deseja em relação aos diretores de escola.

No artigo 14, encontramos as principais atribuições dos diretores para as escolas municipais. Segue o excerto: 
Art. 14 - São atribuições principais dos diretores de educação básica:

I. Dirigir a elaboração e a execução da proposta pedagógica da escola;

II. Administrar o pessoal e os recursos materiais e financeiros da escola, tendo em vista o cumprimento dos fins educacionais;

III. Cumprir e assegurar o cumprimento das disposições legais e das diretrizes da política educacional nacional e do departamento de educação de Conchas;

IV. Controlar a frequência diária dos servidores e atestar a presença nos documentos relativos ao pagamento do pessoal;

V. Assegurar as atividades e o cumprimento dos dias e horas letivos estabelecidos em calendário escolar;

VI. Zelar pelo plano de trabalho do corpo docente;

VII. Prover meios para a execução dos processos de recuperação aos alunos de menor rendimento escolar;

VIII. Promover a articulação da escola com as famílias e comunidade;

IX. Dirigir a escola, cumprindo e fazendo cumprir as leis, regulamentos, o calendário escolar, as determinações superiores e as disposições do plano municipal de educação, de modo a garantir a consecução dos objetivos do processo educacional;

$\mathrm{X}$. Representar o estabelecimento perante as autoridades escolares e municipais;

XI. Presidir as reuniões e festividades promovidas pela escola;

XII. Garantir a circulação e o acesso de toda informação de interesse da comunidade e ao conjunto de servidores e alunos da escola;

XIII. Tomar as providências necessárias para eliminar a evasão e a repetência de aluno;

XIV. Dirigir, no âmbito da escola, as atividades de planejamento, avaliação e desenvolvimento profissional dos docentes;

$X V$. Acompanhar o processo de desenvolvimento de habilidade e competência dos alunos, informando aos pais sobre seus resultados;

$\mathrm{XVI}$. Elaborar estudos, levantamentos qualitativos e quantitativos necessários para o aprimoramento das ações educativas na escola;

XVII. Elaborar, acompanhar e avaliar os planos, programas e projetos voltados para o desenvolvimento do ensino e aprendizagem na escola, garantindo melhoramento continuo nos aspectos pedagógicos, administrativos, financeiros, de pessoal e de recursos materiais;

XVIII. Comunicar ao conselho tutelar todos os casos de maus tratos, negligencia, evasão e baixa frequência relativo aos alunos, garantindo os direitos à proteção, contidos no estatuto da criança e do adolescente;

XIX. Executar outras tarefas correlatas, relacionadas à gestão democrática, determinada pelo superior imediato. (Conchas, 2016)

Nesse artigo, a Secretaria Municipal de Educação expõe dezenove atribuições. Elas referem-se ao desenvolvimento de aspectos administrativos e pedagógicos. Entendemos que ambos aspectos estejam associados, porém, nossas observações assistemáticas revelam que os gestores dedicam-se mais as questões administrativas.

Também é possível constatar que são muitas atribuições ao gestor. A análise dos verbos utilizados nos incisos: dirigir, administrar, cumprir, controlar, assegurar, zelar, prover, promover, representar, presidir, garantir, acompanhar, elaborar, comunicar e executar, revela que o gestor é o representante do município na escola. 


\section{Metodologia}

A pesquisa desenvolvida foi qualitativa. Iniciamos com a revisão literatura e nos aproximamos de autores que questionam a estrutura da escola e o trabalho do gestor. Em seguida analisamos a legislação municipal, que aponta aspectos do trabalho do gestor.

Partindo desse corpus teórico fomos à campo em busca da representação dos professores que vivem o dia a dia na escola do campo. Observamos como é o trabalho docente sem a presença do gestor $e$, as vantagens e desvantagens relatadas por dois professores que lá trabalham.

Desta forma, a nossa intenção foi ter acesso a três versões diferentes: a primeira, baseada no estudo dos autores da área, a segunda, por meio da análise da legislação, e, finalmente, a terceira, decorrente do discurso dos professores.

\section{Caracterização da escola}

A escola localiza-se em um bairro da zona rural distante do centro do município. Nela frequentam 12 alunos do $3^{\circ}$ ao $5^{\circ}$ ano do ensino fundamental. Todos frequentam as aulas na mesma sala e, esta, ainda se divide em biblioteca, cantinho de artes e informática. Os alunos estudam todos juntos, mas de forma diferente, respeitando o seu nível na escola. Como dissemos, a sala apresenta uma divisão de ambientes de estudo. A parte de informática conta com apenas quatro computadores, sendo três para os educandos que se revezam para estudar e realizar as atividades no computador, enquanto, os outros ficam fazendo pintura, lendo livros ou brincando. O outro computador é destinado aos professores fazerem suas atividades.

$\mathrm{Na}$ parte externa da escola tem uma varanda em frente ao refeitório, os banheiros dos meninos e das meninas, uma pequena cozinha e um espaço para realização de brincadeiras e atividades físicas.

A instituição possui dois professores, sendo um no período da manhã e outro no período da tarde e a ajudante geral, que vai um dia sim, outro não. No restante da semana, durante a aula, os professores mesmos cuidam da limpeza e organização de tudo. $O$ almoço é feito no centro do município e transportado até a escola, ficando para os professores servir a alimentação aos alunos. Salientamos que a escola tem um gestor que atende em outra escola, localizada no distrito da cidade. Dificilmente ele comparece, pois todos os problemas e decisões são passadas por telefone ou e-mail para ele. Mas, geralmente, ficam os professores responsáveis pela resolução dos problemas e tomada de decisões.

Os dados foram coletados a partir de três vertentes. A primeira corresponde aos autores ligados à área de gestão, a segunda associada a legislação municipal e a terceira a aplicação de um questionário.

A legislação analisada foi a lei complementar n. 246, de 27 de abril de 2016, que dispõe sobre o plano de carreira e remuneração dos profissionais da Educação Básica do município de Conchas e dá outras providências.

O outro instrumento utilizado foi um questionário com questões fechadas, para conhecer o perfil dos participantes e, questões abertas, para analisar alguns aspectos da escola sem gestor. Eles foram questionados sobre: 
1. O professor é do sexo: ( ) masculino ( ) feminino

2. Sua idade é anos.

3. Você declara-se: ( ) branco ( ) negro ( ) pardo ( ) outro

4. O professor é formado em:

5. Possui Pós-Graduação? ( ) sim ( ) não. Qual?

6. Quanto tempo tem de magistério? Resposta: anos.

7. Quanto tempo trabalha nesta escola? Resposta: anos.

8. Quantos funcionários trabalham nesta escola? Resposta: funcionários.

9. Na sua opinião, qual o papel do diretor de escola?

10. Você sente a falta do diretor na escola ou não? Justifique.

11. Quais as vantagens em trabalhar numa escola sem a presença física do diretor no dia a dia?

12. Quais as desvantagens em trabalhar numa escola sem a presença física do diretor no dia a dia?

13. Na sua opinião, uma escola no meio urbano funcionaria sem o diretor? Justifique.

14. Se você pudesse tomar uma decisão, o que escolheria: trabalhar com o diretor presente na escola ou não? Justifique.

Os dados coletados foram submetidos a Análise de Conteúdo (Moraes, 1999). As etapas realizadas foram: pré-leitura das respostas dos participantes; organização das tabelas; criação de categorias a partir das respostas; interpretação. A categorização foi produzida a partir do agrupamento de dados considerando a semelhança entre eles.

\section{Apresentação e análise dos dados}

\section{O perfil dos participantes}

A pesquisa foi realizada com dois professores que atuam na escola, designados como P1 e P2.

Partindo das respostas, obtivemos: P1 tem 38 anos e P2 tem 62 anos, ambos declarando-se brancos. Os dois pesquisados são formados em Pedagogia, porém, apenas uma respondeu que possui pós-graduação em Psicopedagogia. No magistério P1 respondeu que seu tempo de atuação é de 20 anos, enquanto, que P2 declarou ter 30 anos. Também, P1 disse que trabalha na mesma escola a 3 anos e, P2 a cinco meses, pois declarou ser aposentada da rede estadual e que veio de São Paulo para o interior recentemente.

\section{Apresentação e análise dos dados}

Salientamos que o nosso universo de pesquisa é bastante restrito. Dessa forma, acreditamos iniciar um debate acerca das representações dos professores que vivem essa realidade, para que possamos pensar em outros modos de gestão escolar. Abaixo, no quadro 1, seguem as respostas da questão n. 9, indicadas de P1 e P2. 
Quadro 1 -

Questão 9: Na sua opinião, qual o papel do diretor de escola?

\begin{tabular}{|c|l|}
\hline Professor & \multicolumn{1}{|c|}{ Respostas dos participantes } \\
\hline P1 & $\begin{array}{l}\text { O papel é de gerenciar e organizar o ambiente escolar, auxiliando a todos para } \\
\text { um bom funcionamento. Trabalho em uma escola da zona rural onde o diretor } \\
\text { não é presente. A maioria dos problemas acabo resolvendo sozinha, pois } \\
\text { muitas coisas são de imediato e não tem ninguém com autoridade maior que a } \\
\text { minha para resolver. Para mim o diretor não é necessário quando alguém com } \\
\text { competência e compromisso assume a responsabilidade pelo bom } \\
\text { funcionamento da escola, assumindo o papel do diretor. }\end{array}$ \\
\hline P2 & $\begin{array}{l}\text { Gerenciar, assumir responsabilidades para que professores e funcionários } \\
\text { cumpram cada qual o seu papel, da melhor forma e felizes, quando estamos } \\
\text { sobrecarregados, ficamos impossibilitados de executar bem nossa tarefa. }\end{array}$ \\
\hline
\end{tabular}

Fonte: Autor, 2017.

No quadro 2 seguem as categorias e as frequências.

Quadro 2 -

Categorias de análise.

\begin{tabular}{|l|c|}
\hline \multicolumn{1}{|c|}{ Categorias } & Quantidade \\
\hline Relacionadas à gerenciar & 2 \\
\hline Relacionadas à organização do ambiente escolar & 1 \\
\hline Relacionadas à assumir responsabilidades & 2 \\
\hline
\end{tabular}

Obs.: Os totais indicam o número de respostas e não o de participantes. Fonte: Autor, 2017.

Observando o quadro acima podemos dizer que, para os pesquisados, o gestor tem o papel de gerenciar a unidade escolar, assumir responsabilidades e organizar 0 ambiente escolar.

Também foi identificado, a ligação do gestor ao "bom" funcionamento da escola. Para nós, o "bom" funcionamento associa-se ao coletivo e, não simplesmente a atuação do gestor. Porém, reconhecemos que o seu estilo de gestão impacta as atividades da escola.

Enfim, a organização da escola é responsabilidade de todos, do diretor, do professor, do secretário etc., ou seja, cada um é responsável em organizar seu setor conforme seu papel. 
Quadro 3 -

Questão 10: Você sente a falta do diretor na escola ou não? Justifique.

\begin{tabular}{|c|l|}
\hline Professor & \multicolumn{1}{|c|}{ Respostas dos participantes } \\
\hline P1 & $\begin{array}{l}\text { Não, como trabalho a anos neste lugar, prefiro resolver tudo sozinha, pois } \\
\text { conheço a comunidade escolar, seus problemas e necessidades. Resolvo } \\
\text { quase tudo, como: pedido de material, limpeza escolar, alimentação. Só a } \\
\text { parte burocrática que é resolvida na sede porque aqui não tem secretaria. }\end{array}$ \\
\hline P2 & $\begin{array}{l}\text { Nessa escola que me encontro hoje não, pois tratar-se de uma escola muito } \\
\text { pequena o que faz falta é uma comunicação entre a gestora e funcionários, } \\
\text { para informe de interesse coletivo. }\end{array}$ \\
\hline
\end{tabular}

Fonte: autor, 2017.

No quadro 4 seguem as categorias e as frequências.

Quadro 4 -

Categorias de análise.

\begin{tabular}{|l|c|}
\hline \multicolumn{1}{|c|}{ Categorias } & Quantidade \\
\hline Relacionadas à não sentir a falta do gestor & 2 \\
\hline Relacionadas à preferência em se resolver tudo sozinho (justificativa) & 1 \\
\hline Relacionadas ao conhecimento da comunidade escolar (justificativa) & 1 \\
\hline $\begin{array}{l}\text { Relacionadas à falta de comunicação com o gestor que está na sede } \\
\text { (justificativa) }\end{array}$ & 1 \\
\hline
\end{tabular}

Obs.: Os totais indicam o número de respostas e não o de participantes. Fonte: autor, 2017.

Os participantes indicaram uma preferência por não ter o gestor presente. O P1 justifica que pode resolver os problemas sozinho, já o P2 aponta que sente a falta de comunicação e orientação do gestor. Na resposta do P2, podemos pensar o porquê sentir a falta de comunicação do gestor, se aponta não sentir sua falta? Ou seja, mesmo não querendo ele, ao mesmo tempo sente a falta de ser liderado por alguém.

No quadro 5 indica-se as respostas dos participantes para outra questão.

\section{Quadro 5 -}

Questão 11: Quais as vantagens em trabalhar numa escola sem a presença física do diretor no dia a dia?

\begin{tabular}{|c|l|}
\hline Professor & \multicolumn{1}{|c|}{ Respostas dos participantes } \\
\hline P1 & $\begin{array}{l}\text { As vantagens são poucas, pois o trabalho é dobrado, mas para quem não liga em } \\
\text { pôr a mão na massa, tudo se torna prazeroso. A autonomia é máxima, por mais } \\
\text { que em HTPC venha orientação pedagógica, você tem a liberdade para trabalhar } \\
\text { conforme a necessidade e andamento da turma avançando quando necessário e } \\
\text { diminuindo o ritmo, criando projetos e auxiliando a todos. }\end{array}$ \\
\hline P2 & $\begin{array}{l}\text { Diretor não intervém em minha sala de aula, a presença ou não, não muda meu } \\
\text { comportamento, o pedagógico é responsabilidade do professor. }\end{array}$ \\
\hline
\end{tabular}

Fonte: autor, 2017. 
Abaixo, no quadro 6 , seguem as categorias e as frequências.

Quadro 6 -

Categorias de análise.

\begin{tabular}{|l|c|}
\hline \multicolumn{1}{|c|}{ Categorias } & Quantidade \\
\hline Relacionadas à autonomia & 2 \\
\hline Relacionadas à indiferença & 1 \\
\hline
\end{tabular}

Obs.: Os totais indicam o número de respostas e não o de participantes. Fonte: autor, 2017.

Observando-se o quadro acima podemos constatar que os professores se sentem com mais autonomia. Para um dos pesquisados, a presença ou não do gestor é indiferente, pois ele justifica dizendo que o gestor não intervém em sua sala de aula.

De acordo com a literatura, parece-nos que o gestor tem maior autonomia e, compete a ele a transformação do ensino na instituição. A nossa posição, indica que a escola é construída por um coletivo, pelos gestores, professores, alunos e pais ou responsáveis e, sendo assim, todos são responsáveis pela transformação. Portanto, devemos combater as políticas educacionais que privilegiem apenas alguns. Ou melhor, exigir e trabalhar para que algumas leis sejam concretizadas. Um exemplo, é lutar por condições de trabalho que culminem com uma gestão democrática, algo que já está previsto em lei.

No quadro 7 indicam-se as respostas dos participantes para outra questão.

\section{Quadro 7 -}

Questão 12: Quais as desvantagens em trabalhar numa escola sem a presença física do diretor no dia a dia?

\begin{tabular}{|c|l|}
\hline Professor & \multicolumn{1}{|c|}{ Respostas dos participantes } \\
\hline P1 & $\begin{array}{l}\text { A desvantagem é a responsabilidade por tudo, é ter que assumir problemas, e ter } \\
\text { que resolvê-los. E assumir comunidade escolar e envolvê-la sem ajuda de } \\
\text { ninguém e assim tomar decisões que envolve a todos sem ser remunerado para } \\
\text { isso. }\end{array}$ \\
\hline P2 & $\begin{array}{l}\text { Não haveria desvantagens se houvesse uma boa escola com materiais } \\
\text { adequados, que funcionasse, pois a comunicação hoje está muito fácil. E do outro } \\
\text { lado um diretor competente e conhecedor das suas responsabilidades. }\end{array}$ \\
\hline
\end{tabular}

Abaixo, no quadro 8, seguem as categorias e as frequências.

Quadro 8 -

Categorias de análise.

\begin{tabular}{|l|c|}
\hline \multicolumn{1}{|c|}{ Categorias } & Quantidade \\
\hline Relacionadas à responsabilidade & 1 \\
\hline Relacionadas à assumir problemas & 1 \\
\hline Relacionadas à assumir a comunidade escolar & 1 \\
\hline Relacionadas à tomada de decisões & 1 \\
\hline Relacionadas à infraestrutura & 1 \\
\hline
\end{tabular}

Obs.: Os totais indicam o número de respostas e não o de participantes. Fonte: autor, 2017. 
Para esta questão surgiram categorias que indicam: a maior responsabilidade; assumir mais problemas e a comunidade escolar; tomar decisões e; se preocupar com a infraestrutura.

Segundo a legislação analisada essas atribuições são do gestor, pois, é ele quem tem que zelar pelo plano de trabalho do docente, assumir e promover atividades da escola com a comunidade etc., ou seja, as respostas dos pesquisados sobre as desvantagens se alinham a função do gestor, prescrita em lei.

Analisando a legislação e os autores estudados, podemos perceber que o papel do gestor e do docente é distinto, porém, interligados em prol de um objetivo: atingir a aprendizagem dos discentes. Na escola sem gestor, o fazer o serviço do outro gera uma outra consideração, a de que não ganham a mais para realizar outras funções.

No quadro 9 indica-se as respostas dos participantes para outra questão.

\section{Quadro 9 -}

Questão 13: Na sua opinião, uma escola no meio urbano funcionaria sem o diretor? Justifique.

\begin{tabular}{|c|l|}
\hline Professor & \multicolumn{1}{|c|}{ Respostas dos participantes } \\
\hline P1 & $\begin{array}{l}\text { Não, como já fui diretora de uma escola grande, percebi que a nossa cultura não } \\
\text { permite que um ambiente com muitos funcionários funcione sem um líder. Em } \\
\text { qualquer ambiente tem pessoas boas e ruins, uns que assumem o compromisso e } \\
\text { outros que não estão nem ai. Os ruins contaminam os bons se não tiver uma } \\
\text { orientação indicando o caminho. }\end{array}$ \\
\hline P2 & $\begin{array}{l}\text { Não, no meio urbano há problemas que ultrapassam os muros escolares, como } \\
\text { brigas, drogas, seria uma atribuição a mais ao professor e, economia monetária } \\
\text { para o empregador. }\end{array}$ \\
\hline
\end{tabular}

Fonte: autor, 2017.

No quadro 10 seguem as categorias e as frequências.

Quadro 10 -

Categorias de análise.

\begin{tabular}{|l|c|}
\hline \multicolumn{1}{|c|}{ Categorias } & Quantidade \\
\hline Relacionadas ao não funcionamento sem o gestor & 2 \\
\hline Relacionadas ao auxílio de um líder (justificativa) & 1 \\
\hline Relacionadas ao compromisso das pessoas (justificativa) & 1 \\
\hline Relacionadas aos problemas (justificativa) & 1 \\
\hline
\end{tabular}

Obs.: Os totais indicam o número de respostas e não o de participantes. Fonte: autor, 2017.

No meio urbano, normalmente, as escolas são maiores. Esse fato levou os participantes a se posicionarem que não é possível dela funcionar sem um gestor presente todos os dias. Segundo a literatura especializada, a estrutura da escola já é planejada para se ter um gestor, no qual desenvolve o seu trabalho, segundo as diretrizes preestabelecidas pelos órgãos superiores. Logo, a representação docente, construída historicamente, associa-se a sentir a falta de um líder. 
No quadro 11 indica-se as respostas dos participantes para outra questão.

Quadro 11 -

Questão 14: Se você pudesse tomar uma decisão, o que escolheria: trabalhar com o diretor presente na escola ou não? Justifique.

\begin{tabular}{|c|l|}
\hline Professor & \multicolumn{1}{|c|}{ Respostas dos participantes } \\
\hline P1 & $\begin{array}{l}\text { Se fosse em uma escola na zona rural falaria com certeza que um diretor não é } \\
\text { necessário, mas em uma escola na zona urbana um diretor ainda é necessário } \\
\text { para levar as pessoas a terem um bom senso e resolverem o melhor para os } \\
\text { alunos. Como cada um tem uma opinião e ainda estamos nessa cultura de ter que } \\
\text { mandar. }\end{array}$ \\
\hline P2 & $\begin{array}{l}\text { Depende muito da circunstância, há diretores competentes que nos fazem falta e } \\
\text { quem assumira a parte não pedagógica. Para eu trabalhar numa escola sem } \\
\text { gestor, teria que ter um bom salário e ser conhecedor de muitos assuntos, leis. } \\
\text { Nessa escola que me encontro prefiro sem. }\end{array}$ \\
\hline
\end{tabular}

Fonte: autor, 2017.

Abaixo, no quadro 12, seguem as categorias e as frequências.

Quadro 12 -

Categorias de análise

\begin{tabular}{|l|c|}
\hline \multicolumn{1}{|c|}{ Categorias } & Quantidade \\
\hline Relacionadas à localização e ao contexto em que a escola está inserida & 2 \\
\hline Relacionadas à competência do gestor (justificativa) & 1 \\
\hline Relacionadas à cultura do mandar (justificativa) & 1 \\
\hline Relacionadas à maior remuneração (justificativa) & 1 \\
\hline
\end{tabular}

Obs.: Os totais indicam o número de respostas e não o de participantes. Fonte: autor, 2017.

As categorias demonstram que a localização e o contexto em que a escola está inserida tem um forte impacto. Os dois participantes preferem trabalhar sem o gestor na escola do campo, porém, na cidade, preferem a sua presença. A cultura do mandar é mencionada por um pesquisado. O discurso mostra que a divergência de opiniões na escola, ainda exige um juiz que direcione. Isso mostra a dificuldade de as escolas se organizarem e fortalecerem o coletivo. Parece-nos que muitos gestores entram no cargo pensando que é só mandar.

Um participante também questiona a remuneração. Afirma que precisa ganhar mais pelo desenvolvimento das atividades, que deveriam ser realizadas pelo gestor. Neste caso, concordo com os docentes e pesquisadores que defendem a ideia de que a profissão de professor precisa ser valorizada e melhor remunerada.

Por fim, entendemos que o gestor deva combater a "cultura do mandar" e incentivar a colaboração entre aqueles que estão no chão da escola.

\section{Considerações finais}

O objetivo deste estudo foi investigar o funcionamento de uma escola do campo sem a presença do gestor. Os autores estudados indicam dois posicionamentos. Aqueles que defendem que cabe ao gestor liderar e aqueles que defendem que cabe a ele mediar. Observamos que a legislação municipal enfatiza, por meio de uma lista de atribuições, a 
dimensão técnica. A dimensão política é destacada pelos autores, que incentivam a participação dos órgãos colegiados. A proposta de Paro sobre o conselho diretivo é interessante.

Os pesquisados salientaram que na escola do campo, onde atuam e frequentam poucos estudantes, a escola sem gestor funciona e apresentam como principal vantagem a autonomia. Já na cidade disseram que esse modo de gestão é mais difícil de funcionar. Um dos professores (P1) ressaltou que a questão é cultural, sendo que a maioria dos professores, funcionários e alunos se acomodam e esperam receber ordens para realizarem suas tarefas.

Por fim, o nosso estudo, ainda que pontual e restrito a um contexto específico, provoca uma discussão sobre a possibilidade de outros modos de gestão escolar. Parecenos um desafio, entre os profissionais da educação, a construção de representações e práticas que questionem a estrutura da escola e o papel do gestor. Essa temática merece mais atenção e um maior aprofundamento.

\section{Referências}

ABDIAN, Graziela Zambão; OLIVEIRA, Maria Eliza Nogueira; JESUS, Graziela de. Função do diretor na escola pública paulista: mudanças e permanências. Educação \& Realidade, Porto Alegre, v. 38, n. 3, 2013, p. 977-998.

CONCHAS. Lei complementar n. 246, de 27 de abril de 2016. Dispõe sobre o plano de carreira e remuneração dos profissionais da Educação Básica do município de Conchas e dá outras providencias. Conchas: Prefeitura Municipal, 2016.

LIBÂNEO, José Carlos. Organização e gestão da escola: teoria e prática. São Paulo: Heccus, 2015.

MARANGONI, Ricardo Alexandre. Gestores escolares: representações e práticas. Curitiba: CRV, 2017.

MORAES, Roque. Análise de conteúdo. Revista Educação, Porto Alegre, v. 22, n. 37, p. 7-32, 1999.

PARO, Vitor Henrique. Crítica da estrutura da escola. São Paulo: Cortez, 2011.

Ronaldo Gomes Pinto é licenciado em Pedagogia pela Faculdade de Conchas.

Endereço: Rua Itaipu, 157 - 18570-000 - Conchas - SP - Brasil.

E-mail: ronaldo.gomes129@gmail.com.

Ricardo Alexandre Marangoni é professor na Faculdade de Conchas e estudante de pós-doutorado em Educação na Universidade Federal do Paraná.

Endereço: Rua Itaipu, 157 - 18570-000 - Conchas - SP - Brasil.

E-mail: ramarangoni@hotmail.com.

Recebido em 24 de abril de 2018.

Aceito em 18 de julho de 2018.

(c) (i) 